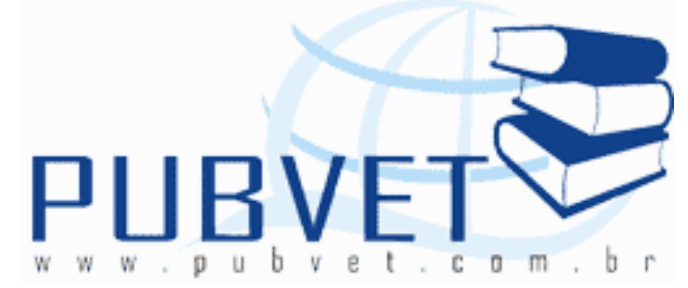

PUBVET, Publicações em Medicina Veterinária e Zootecnia.

\title{
O turismo rural e as linhas crédito para produção agropecuária no Brasil
}

\section{Alonso Almeida Basílio da Silva ${ }^{1}$, Max Leandro de Araújo Brito², Maria Valéria Pereira de Araújo 3}

${ }^{1}$ Graduando em administração pela UFRN

${ }^{2}$ Docente do Depad-UFRN

${ }^{3}$ Docente do PPGTUR-UFRN

\section{Resumo}

A pesquisa objetiva analisar o oferecimento de linhas de crédito para produção agropecuária. A metodologia consiste na revisão da literatura que aborda a administração rural, administração financeira e linhas de crédito, além de aplicação de análise de conteúdo em sites de três bancos que atuam com programas de crédito rural, tratando-se de uma pesquisa qualitativa. Dentre os resultados obtidos estão que mesmo com as inúmeras linhas de crédito disponíveis no Brasil o pequeno produtor ainda não dispõe de informação suficiente para ter acesso a esses financiamentos. A pesquisa conclui que as linhas de créditos oferecidas foram bem elaboradas, para que cada uma possa atender a um público específico.

Palavras-chave: Assistencialismo; Rural; Crédito. 


\title{
The rural tourism and the credit lines for agricultural production in Brazil
}

\begin{abstract}
The research aims to analyze the offer of credit lines for agricultural production. The methodology consists in the literature review that addresses the rural administration, financial management and credit lines, and application of content analysis on sites of three banks that operate in rural credit programs, in the case of a qualitative research. Among the results are that even with the numerous lines of credit available to small producers in Brazil does not yet have enough information to access these funds. The research concludes that the credit lines offered were well prepared, so that each can meet a specific audience.
\end{abstract}

Keywords: Welfare; Rural; Credit.

\section{INTRODUÇÃO}

Nos dias atuais tornou-se mais fácil de conseguir financiamentos para o setor rural, através de programas oferecidos pelo governo federal junto aos bancos de todo o país, mas nem sempre foi assim, todavia que apenas em 1938 foi que o primeiro banco começou a disponibilizar financiamentos para o setor agropecuário (SANTOS, 1986). Dessa forma é muito importante o entendimento de como o produtor agropecuário deve trabalhar com as linhas de créditos disponíveis para a produção agropecuária, o que implica também no aproveitamento das informações para o desenvolvimento do turismo no ambiente rural.

As linhas de crédito para a produção agropecuária estão direcionadas a todos os tipos de produtores rurais, pequenos, médios e de grande porte. São financiamentos que foram elaborados para atender os clientes de acordo com as suas necessidades específicas. De acordo com o Plano Agrícola e Pecuário 2011/2012 brasileiro elabora pelo Ministério da Agricultura, Pecuária e 
Abastecimento, para a safra 2011/2012 o governo vai manter e ampliar a ação de seus instrumentos de políticas públicas, notadamente o crédito rural, bem como os mecanismos de apoio à comercialização e gestão de risco rural. Esse incentivo pode contribuir bastante também com o desenvolvimento do turismo rural (PLANO AGRÍCOLA E AGROPECUÁRIO, 2012).

Levando em consideração o contexto apresentado, o presente trabalho tem por objetivo analisar o oferecimento de linhas de crédito para produção agropecuária. Para tanto, o referencial teórico fundamentou-se principalmente em pesquisa bibliográfica realizada a autores que publicaram sobre a Administração Rural, Administração Financeira e Linhas de Crédito Rural.

A metodologia consiste na revisão da literatura que aborda marketing social, políticas públicas, programas assistencialistas rurais, além de aplicação de análise de conteúdo em sites do governo federal do Brasil, tratando-se de uma pesquisa qualitativa.

O presente trabalho tem a função de analisar e fornecer informações sobre as linhas de crédito rurais disponíveis no Brasil, permitindo que estudantes de administração e cursos relacionados a área rural venham a adquirir conhecimento sobre essas linhas de financiamentos.

O trabalho se estrutura com uma revisão inicial sobre administração rural, administração financeira, linhas de crédito, seguida da metodologia, resultado e análises, e por fim a conclusão.

\section{ADMINISTRAÇÃO RURAL}

De acordo com Hoffmann, Serrano e Neves (1989), a Administração Rural é o estudo que considera a organização e operação de uma empresa agrícola que tem como objetivo utilizar e manusear de forma mais eficiente os recursos para obter resultados compensadores e contínuos. Hoffmann, Serrano e Neves (1989), também observa que a Administração Rural implica em duas funções diferentes, que são: 
1) Organização que se refere especificamente à função de criar o esquema geral ou plano de produção.

2) Coordenação e supervisão (atividade operacional, em oposição à atividade organizacional), que se refere à administração propriamente dita, isto é, a função de pôr em execução o esquema e de se fazer aqueles ajustamentos que são necessários com o fim de obter o máximo rendimento econômico relativo à empresa agrícola considerada como um todo.

Segundo Antunes e Engel (1999), o conceito geral de Administração Rural está sendo relacionado de acordo com a necessidade de controlar e gerir um número cada vez maior de atividades que podem ser desenvolvidas dentro de uma propriedade do setor agropecuário.

Praticamente, qualquer tipo de ação tomada pelo proprietário ou administrador de uma propriedade no sentido de controlar alguma coisa (seja o pedigree de seus animais, o balanceamento das rações utilizadas ou suas despesas com mão-de-obra), vem sendo considerada como uma atividade ligada a práticas de Administração Rural. (ANTUNES e ENGEL, 1999).

Crepaldi (2005), afirma que o conhecimento das condições de mercado e dos recursos naturais dá ao produtor rural os elementos básicos para o desenvolvimento de sua atividade econômica. Cabe a ele agora decidir o quê, quanto e como produzir, controlar a ação após iniciar a atividade e, por ultimo avaliar os resultados alcançados e compará-los com os previstos inicialmente.

Crepaldi (2005), também descreve que é possível constatar que a administração rural no Brasil ainda se desenvolve dentro de critérios bastante tradicionais ou com um padrão de desempenho inaceitável. Essa característica não é atributo apenas de pequenos produtores rurais, prevalecendo também entre as médias e grandes empresas, com economia de mercado e elevados níveis de renda. 


\section{ADMINISTRAÇÃO FINANCEIRA}

A administração financeira é responsável por todo o dinheiro que circula na organização. A função financeira de uma organização tem por objetivo a proteção e a utilização eficaz dos recursos financeiros, o que inclui a maximização do retorno dos acionistas, no caso de empresas. Ao mesmo tempo, a função financeira busca manter certo grau de liquidez, para que a organização consiga cumprir seus compromissos. A função financeira abrange as decisões de financiamento (busca de recursos), investimento (aplicação), controle do desempenho financeiro e destinação dos resultados. (MAXIMIANO, 2006).

Segundo Gitmann (1997), a administração financeira diz respeito às responsabilidades do administrador financeiro numa empresa. Os administradores financeiros administram ativamente as finanças de todos os tipos os tipos de organização, financeiras ou não-financeiras, privadas ou públicas, grandes ou pequenas, com ou sem fins lucrativos. Eles desempenham uma variedade de tarefas, tais como orçamento, previsões financeiras, administração do caixa, administração do crédito, análise de investimentos e captação de fundos.

O administrador financeiro de uma organização com capital aberto trabalha em função de maximizar os lucros dos seus acionistas, trabalhando de acordo com os melhores interesses dos mesmos. Logo, de acordo com Ross, Westerfield e Jordan (1998), o objetivo da administração financeira, numa sociedade por ações, é maximizar o valor corrente de cada ação existente.

Ross, Westerfield e Jordan (1998), afirmam ainda que a finalidade da empresa é criar valor para o seu proprietário. 


\section{LINHAS DE CRÉdITO PARA O DESENVOLVIMENTO AGROPECUÁRIO E O TURISMO RURAL}

De acordo com Santos (1986), a concessão de financiamentos rurais subordina-se a que o interessado tenha conhecimento da atividade, suprível pela assistência técnica; imóvel adequado à exploração; condições ecológicas favoráveis; vantagens de maior rendimento produtivo e haja segurança da livre comercialização e escoamento da produção. Os financiamentos devem propiciar condições para que o produtor desenvolva suas explorações de maneira racional, com o máximo de aproveitamento dos fatores técnicos, visando obter renda líquida mais elevada.

Santos (1986) também enfatiza que, normalmente essas operações, quando propostas por pessoas físicas, serão conduzidas pelas agências locais do agente financeiro, jurisdicionantes do imóvel rural considerado. Em se tratando de proponente, pessoa jurídica, a base jurisdicionante do atendimento será a de onde se encontra situado o escritório central ou a sede da empresa.

De acordo com dados do Plano Agrícola Agropecuário 2011/2012 brasileiro, fornecido pelo Ministério da Agricultura, Pecuária e Abastecimento, revela que a safra de 2010/2011 vai levar o Brasil a novos recordes na produção de grãos no país, produzindo 161,5 milhões de toneladas. Esse é um resultado que coloca o país com uma safra $8,2 \%$ acima da anterior, esse aumento mantém a produção agropecuária brasileira entre as mais prósperas do mundo (PLANO AGRÍCOLA E AGROPECUÁRIO, 2012).

Na safra 2011/2012 o governo federal disponibilizará R\$ 107,2 bilhões para a agricultura comercial, num aumento de $7,2 \%$ se comparado a safra anterior. Esses recursos que estão sendo oferecidos serão divididos em: custeio e comercialização $R \$ 80,2$ bilhões, investimentos $R \$ 20,5$ bilhões e linhas especiais R $\$ 6,5$ bilhões (PLANO AGRÍCOLA E AGROPECUÁRIO, 2012).

As principais fontes de financiamento para tal montante de recursos estão distribuídas entre o Banco Nacional de Desenvolvimento Econômico e Social (BNDES), Fundos Constitucionais de Financiamento, Recursos 
Obrigatórios dos Depósitos à Vista, Poupança Rural e Programa Nacional de Apoio ao Médio Produtor Rural (Pronamp) (PLANO AGRÍcOLA E AGROPECUÁRIO, 2012).

De acordo com Vezzani (2008) o turismo rural pode impulsionar os espaços rurais, não como um motor de desenvolvimento, mas na forma de um elemento complementar para outras atividades de caráter tradicional como: a agricultura, a criação de gado, o artesanato, a pequena indústria, etc., podendo, ainda, impulsionar os benefícios sociais, culturais e ambientais. Sendo que para esses objetivos sejam alcançados, é necessário que se adotem critérios de sustentabilidade e decidir que é possível um desenvolvimento continuado ao mesmo tempo em que se preservam os recursos naturais existentes.

\section{METODOLOGIA}

O presente trabalho se propõe a analisar o oferecimento de linhas de crédito para o desenvolvimento agropecuário. Portanto, trata-se de uma pesquisa exploratória (ROESCH, 2005) e descritiva qualitativa.

Os dados foram coletados através de visitas a três sites de bancos que oferecem linhas de crédito para o incentivo de atividades agropecuárias no Brasil e também foram levantadas referências bibliográficas de autores que tratam do assunto citado anteriormente.

Em relação ao tratamento dos dados, foi realizada uma descrição do que foi observado nos sites para ser efetuada uma comparação entre os bancos visitados.

Os dados foram tratados através da análise do conteúdo (BARDIN, 2002), sem a presença de softwares específicos. 


\section{RESULTADOS E ANÁLISES}

Para coletar as informações necessárias para realizar a análise desse trabalho foram realizadas consultas a três sites de bancos, Banco A, B e C.

O Banco A teve suas atividades inicializadas no ano de 1964. Na década de 1980 o Banco passa a ser uma instituição financeira múltipla, com carteira comercial, de financiamento de câmbio e de crédito imobiliário e ao longo dessa década inaugura 25 novas agências em todo o Brasil. Em 1996 começa a internacionalização do Banco A. No ano de 2009 o Banco A completa 45 e registra um crescimento expressivo de suas operações, com destaque para as captações. Instituição inicia importante projeto de reestruturação de seu parque tecnológico. No ano de 2011 o Banco A dá continuidade ao seu projeto de inovação tecnológica e inaugura mais um datacenter, um dos mais modernos do país.

O Banco B foi o primeiro banco a operar no País e, hoje, é a maior instituição financeira do Brasil. Em seus mais de 200 anos de existência, acumulou experiências e pioneirismos, participando vivamente da história e da cultura brasileira. Em 1996 A Empresa é reestruturada para se adaptar à nova conjuntura advinda do Plano Real e a conseqüente queda da inflação que afetou todo o sistema bancário. Para adequar o quadro de pessoal, foi lançado o Programa de Desligamento Voluntário - PDV. Dentro do PDV, 13.388 funcionários foram desligados no ano. Com lucro líquido de 11,7 bilhões e ativos totais de 811,2 bilhões, o Banco B encerrou 2010 como líder no Sistema Financeiro Nacional, destacando sua atuação no crédito com $19,8 \%$ de participação de mercado. Essa liderança foi alcançada devido à ênfase no financiamento a pessoas físicas, especificamente crédito consignado, financiamento a veículos e financiamento imobiliário. Além de manter-se como líder de mercado, o foco em pessoas físicas contribui para o crescimento da margem financeira do Banco, com melhoria na qualidade de sua carteira.

Os anos 50 marcam o início da trajetória do Banco C. Na época, foi realizado amplo estudo sobre a economia, cuja apreciação constituiu a base 
científica para o nascimento da instituição. Com apoio de cooperação técnica de missões internacionais, iniciaram-se atividades pioneiras, entre as quais a experiência do crédito rural supervisionado, em articulação com a ANCAR Associação Nordestina de Crédito e Assistência Rural, a assistência a cooperativas e a introdução da prática de elaboração e avaliação de projetos como pré-requisito para a obtenção de financiamentos. Em 2006 que foi o ano que marcou a consolidação da trajetória de crescimento das operações de empréstimos e financiamentos iniciada em 2003, com a contratação de operações globais que somaram $R \$ 7,3$ bilhões, sendo de $R \$ 4,6$ bilhões do Fundo Constitucional de Financiamento do Nordeste (FNE). Como conseqüência, o Banco inicia a estruturação de novos programas com fontes alternativas para o financiamento do desenvolvimento da Região, utilizando fontes.

No Banco A nota-se que ele detém de linhas de crédito para grandes produtores do setor agropecuário, mas também essa instituição financeira tem uma linha de crédito especial para pessoas físicas que querem realizar investimentos nesse setor, é um programa que é denominado de Rural LCA (Letra de Crédito do Agronegócio), o Rural LCA é um título de renda fixa, emitido pelo próprio banco, que tem como principal objetivo atingir pessoas que pretendem fazer investimentos a partir de $R \$ 50.000,00$, que são isentas de pagamento de imposto de renda.

Quanto aos créditos oferecidos pelo Banco A percebe-se que ele dedica um grande espaço aos agropecuaristas de pequeno, médio e grande porte, isso é muito importante, principalmente para os pequenos produtores, todavia que encontram grandes dificuldades para desenvolver suas atividades comerciais, pois possui pouco capital para realizar esses investimentos e têm a necessidade de recorrer as linhas de crédito oferecidas por essas instituições financeiras.

O Banco B dispõe de várias modalidades de financiamento para o atendimento das necessidades correntes na produção agropecuária. As linhas de custeio financiam as despesas do dia a dia durante a produção, permitindo 
recursos para utilização em qualquer período da atividade. As Linhas de crédito disponíveis do banco são: Pronaf, PRONAMP e Exportação, FINAME, BNDES, FCO Rural, Desconto de NPR/DR, Linha especial para comercialização, EGF, CPR, Adiantamento a cooperados, Financiamento à exportação ACC/ACE, exportação pré-pagamento e importação. Entre as linhas de crédito oferecidas pelo banco destacam-se: o FINAME, que são linhas que visa incentivar 0 agronegócio nas diversas regiões do País. Elas são destinadas ao financiamento de máquinas, equipamentos e projetos para desenvolvimento da atividade agropecuária e contam com condições entre as melhores do mercado, oferecendo prazos de até 90 meses para a quitação total do débito. Outro programa de destaque é o Custeio Agropecuário que são linhas designadas para à cobertura das despesas normais das atividades agrícolas e pecuárias. São despesas que decorrem do dia a dia da produção, devendo o pagamento ocorrer dentro do ciclo produtivo.

Observa-se que o Banco B também procura atender a todas as classes de produtores agropecuários e oferece prazos maiores para a quitação dos financiamentos comparando aos prazos oferecidos pelo Banco A. Em seus programas de crédito o banco procura dar assistência ao produtor desde 0 início da produção até a sua comercialização para o mercado.

O Banco $C$ foi criado para atender especialmente o público rural e a população nordestina, por isso dentre esse três bancos ele é o que oferece maior incentivo ao agropecuário com linhas de crédito especiais para esse público, dentre elas destacam-se o Agroamigo, que é um programa de Microfinança Rural, operacionalizado em parceria com o Instituto Nordeste Cidadania e com Ministério do Desenvolvimento Agrário (MDA). Trata-se de uma iniciativa pioneira no Brasil que visa à concessão de financiamento para área rural, adotando metodologia própria de atendimento, cuja principal premissa consiste na concessão de crédito orientado e acompanhado. Outra linha de destaque do Banco $C$ é o Pronaf (Programa Nacional de Fortalecimento da Agricultura Familiar) que é um programa assistencial que atende as famílias rurais. 
O Banco C apresenta programas de linhas de crédito destinados principalmente para o produtor que quer realizar pequenos investimentos e ainda precisa de assistência para o manuseio da sua produção e depois comercializá-la.

\section{CONCLUSÃO}

Por fim, a pesquisa conclui que o oferecimento de linhas de crédito para a produção agropecuária é de grande importância não apenas para os grandes e médios agropecuaristas do país, mas também em especial para os pequenos produtores, onde os bancos dispõem de vários programas de financiamento para esses agropecuários e de programas assistenciais onde ensinam ao pequeno produtor gerir a sua produção até comercializá-la.

Dentre as limitações encontradas para a realização da pesquisa está a dificuldade de encontrar literaturas específicas das áreas abordadas.

Para estudos posteriores sugere-se um maior enfoque na questão do desenvolvimento do turismo rural.

\section{REFERÊNCIAS}

ANTUNES, L. M. Manual de administração rural - custos de produção. Guaíba: agropecuária, 1999.

BARDIN, L. Análise de conteúdo. Lisboa: Edições 70, 2002.

CREPALDI, S. A. Contabilidade rural - uma abordagem decisorial. São Paulo, Atlas. 2005.

GITMANN, L. Princípios de administração financeira. 7 ed. São Paulo: Harbra, 1997.

HOFFMANN, R.; SERRANO, O.; NEVES, E. M. Administração da Empresa Agrícola. São Paulo: Pioneira, 1987.

MAXIMIANO, A. C. Administração para empreendedores. São Paulo: Pearson Prentice Hall, 2006.

PLANO AGRÍCOLA E AGROPECUÁRIO 2011/2012. Disponível em: < http://www.agricultura.gov.br/politica-agricola/plano-agricola> Acesso em: 12 fev. 2012.

ROESCH, S. M. A. Projeto de estágio e de pesquisa em administração: guia para estágios, trabalhos de conclusão, dissertações e estudos de caso. 3 ed. São Paulo: Atlas, 2005. 
ROSS, S. A.; WASTERFIELD, R. W.; JORDAN, B. D. Princípios de administração financeira. São Paulo: Atlas,1998.

SANTOS, A. Linhas do crédito rural no Brasil - Princípios e Prática. São Paulo: Resenha Tributária, 1986.

VEZZANI, M. A. Turismo rural e responsabilidade ambiental e ecológica no espaço rural brasileiro. Caderno Virtual de Turismo, v. 8, n. 1, 2008. 